\title{
Research on the Impact of Mobile Social Networking Media on the Development of Library Industry
}

\author{
Wang Qiong, Chen Wei \\ Library, Dongguan University of Technology, Dongguan, China \\ Email address: \\ wq19661965@163.com (Wang Qiong)
}

\section{To cite this article:}

Wang Qiong, Chen Wei. Research on the Impact of Mobile Social Networking Media on the Development of Library Industry. International Journal of Science, Technology and Society. Vol. 6, No. 4, 2018, pp. 63-71. doi: 10.11648/j.ijsts.20180604.11

Received: July 10, 2018; Accepted: September 7, 2018; Published: October 22, 2018

\begin{abstract}
In the era of mobile Internet, digital network of social media has become the mainstream of the widely used communication tool which is used in a wide range in the learning and life. This paper study aim the construction social media library, users' data was investigated extensively; the systematic analysis method was utilized for further analysis. The causes for the rapid growth of social media is illustrated, and the impact of social media on the library industry is analyzed. Moreover, based on the current situation of library industry and social media, the necessity and the possibility of the cooperation between these two parties is analyzed in the real situation. As a result, this paper proposes the new concept of the social media library and summaries the future development trend of the library. The conclusion is that libraries should make full use of social media technology and a large user base and combine library knowledge with authoritative and reliable content to establish a sound channel for knowledge dissemination. At the same time, this paper lists the challenges for the all-round cooperation between library industry and social media, including the copyright problems. And the reasonable solution is provided such as technical implementation method, the appropriate business model.
\end{abstract}

Keywords: Social Media, Social Networking, Social Media Library, Library, Research

\section{Introduction}

In the era of mobile Internet, real-time interaction, sharing and utilization of information through the network have become the choice of more and more people. As an emerging mobile network interaction tool, social media fully satisfies the real-time interaction of network communication and people's social relationship needs. Through intelligent mobile network interaction devices, it provides users with independent control and fast interaction in an extremely convenient way to make social media experience explosive growth in the number of users and the utilization frequency within a very short period. There is no doubt that social media is profoundly influencing modern people and all walks of life. It also inevitably has a significant impact on the library industry. Social media library will appear, and its construction and development is the vital proposition of library which needs to study and think.

\section{The Development of Social Media and Its Impact on the Library Industry}

\subsection{Development Status of Social Media and Mobile Network Users}

At present, Facebook, Twitter, WeChat, and microblog are all typical social media networks.

Facebook announced in its financial report for the first quarter that its monthly active users (MAU) on the mobile side have reached 1.01 billion, an increase of $34 \%$ over the previous year. It shows the trend of Facebook users moving from the desktop side to the mobile side. More and more users are accessing Facebook through smartphone and tablet PC instead of a desktop computer, and Facebook's monthly active users on the desktop side and the mobile side has reached 1.28 billion. [1] In Twitter's financial report for the first quarter of 2014 shows that the company's monthly active users (MAU) have increased to 255 million, of which the active mobile users on the mobile side has risen to 198 million, accounting 
for $78 \%$ of the total MAU. Currently, it has more than 200 million average daily active users who contribute 400 million pieces of information every day. [2]

As a typical representative of Chinese social media, WeChat released its first version on January 21, 2011, and on January 15, 2018, Tencent officially announced that its number of users had exceeded 800 million. [3] As of April 2014 , sources at Tencent said that the number of WeChat users had surpassed 600 million, and the active online users of Tencent QQ had reached 200 million. This amazing user growth rate fully highlighted the appeal of social media to the audience. Another representative of Chinese social media Sina microblog was launched in 2006 and officially listed on NASDAQ in New York on April 17, 2014. According to the data released by Sina microblog, as of March this year, the monthly active users of microblog was 143.8 million, with daily active users of 66.6 million. Sina microblog has more than 80,000 microblog accounts of various government agencies and officials. Even the internationally renowned institutions such as the United Nations and Agence France Presse (AFP) push the latest news every day on Sina microblog in both Chinese and English.

According to the report released by the China Internet Network Information Center in March 2018, as of June 2018, the number of Internet users in China reached 802 million, of which the number of mobile Internet users reached 788 million, with an annual growth rate of $4.7 \%$. The proportion of netizens surfing the internet on mobile phones increased from $97.5 \%$ to $98.3 \%$. Mobile phones maintain the highest usage rate of Internet terminals. In 2017, 70.73 million new users were added, and the proportion of Internet users using mobile phones was as high as $73.3 \%$, which was higher than the percentage of netizens using other devices to access the Internet. Among the netizens in China, the rural population is 177 million, accounting for $28.6 \%$. In recent years, the number of Internet users in China has been on the increase. In 2013, the per capita online time of netizens in China was 25.0 hours per week, an increase of 4.5 hours compared with the previous year. As of December 2013, the number of mobile search users in China had reached 365 million, an increase of 73.65 million compared with the end of 2012, with a growth rate of $25.3 \%$; the mobile search usage rate was $73.0 \%$, an increase of 3.6 percentage points from the end of 2012. With the development of the mobile Internet, the search behavior of Internet users has shifted from the PC side to the mobile side.

\subsection{The Development Background of Social Media and Its Impact on the Library Industry}

Through analysis, it is found that the rapid development of Chinese social media mainly stems from the following three background factors:
First, the government has positioned the network infrastructure as a national development strategy. On August 1, 2013, the State Council issued the "Broadband China" Strategy and Implementation Plan, which unprecedentedly positioned broadband as national public infrastructure which has the same status as water, electricity and roads. "Broadband" has officially become the main carrier of information dissemination in the whole society in the future. According to the requirements of the "Broadband China Strategy Plan", the cities in China will basically realize fiber-to-the-building and broadband-to-village in 2015. By 2020 , broadband networks will cover both urban and rural areas, which will greatly reduce the Internet access charges.

Second, intelligent network mobile devices are rapidly gaining popularity. The universal application of smart network mobile devices, especially smartphones, has accelerated the penetration of network applications into social groups. The technology and purchase threshold of mobile phones are lower compared to computers, which is an essential way for the Internet to penetrate into rural areas and low-income groups. The popularity of smartphones provides conditions for accessing the Internet. According to the data released by the Ministry of Industry and Information Technology, from January to October 2013, China's smartphone shipments reached 348 million, and the sales volume of which maintained rapid growth. In November 2013, 3G mobile phone users reached 386 million, an increase of 154 million compared with the same period of last year.

Third, social media has become an essential mean of communication in the mobile Internet era. Social media features the convenience of instant communication and the flexibility of application, which can replace telephone and text messages to a large extent, so the usage frequency and the stickiness of Internet users are both increased. Also, the continuous linkage of social media with the traditional media and people's daily life habits, such as shopping, hailing a taxi, payments, playing games, etc., which further increases the user's dependence on social media, making the user scale continue to grow.

In fact, users of mobile social networking media are quickly becoming the mainstay of online users, and this will undoubtedly have a profound impact on the library industry.

\section{Development Situations of the Library in the Social Media Environment and the Relevant Thinking}

\subsection{Situation and Problems Faced by the Library Industry}

The "National Library of China Yearbook 2012" data shows: 


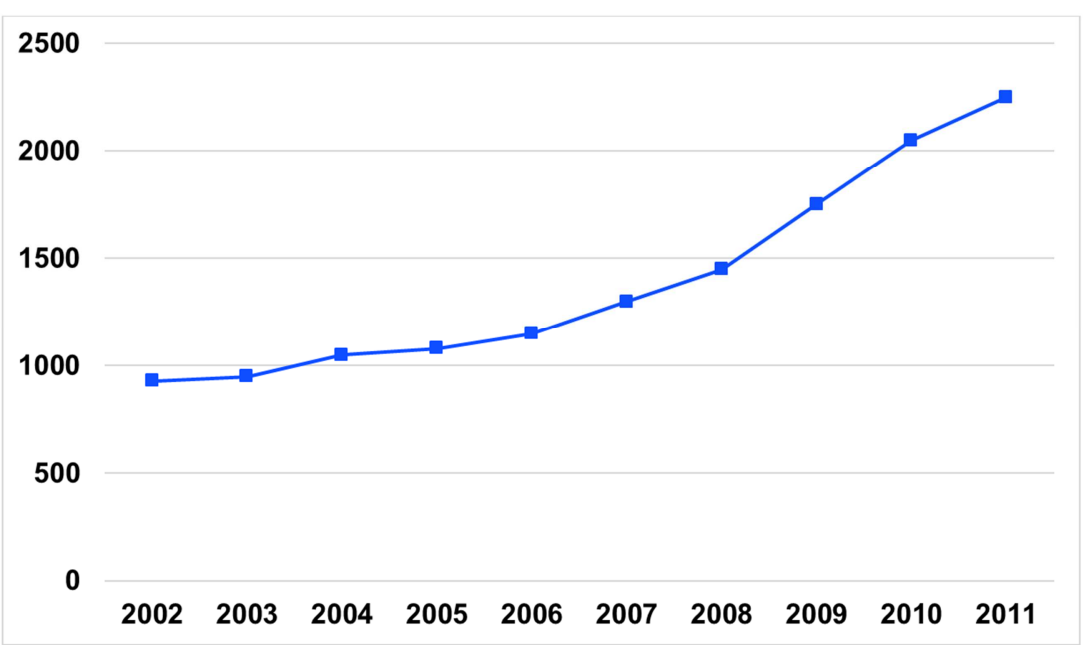

Figure 1. Number of registered users of public libraries in China (based on the number of library cards issued) (unit: 10,000).

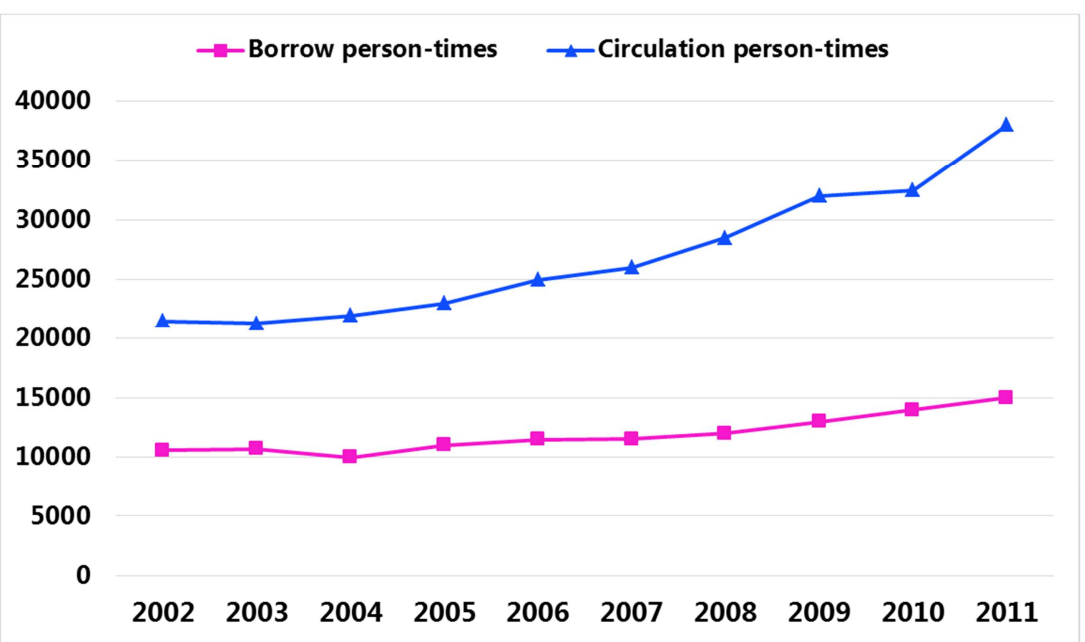

Figure 2. Circulation person-time of public libraries in China (unit: 10,000 person-times) Borrow person-times|Circulation person-times.

According to the data from above two charts, the number of public library users nationwide more than doubled in the decade from 2002 to 2011, reaching 23 million; the annual circulation person-times has increased by about twice, with the number reaching nearly 400 million. The result reflects the steady growth of library users, but it is incomparable to the rapid growth of social media users.

$\mathrm{n}$ recent years, the Chinese government has attached great importance to cultural development, bringing a hard-won opportunity for library development. The library industry has obtained unprecedented policy and financial support. As a social knowledge guarantee institution, the library is also making great efforts to fully realize human rights such as equal access and intellectual freedom. The digital library construction, knowledge sharing projects, and joint regional libraries carried out by the state, provincial and municipal governments, including some specific measures adopted in the library industry, such as car libraries, ATMs in the library and mobile libraries, etc., are all intended to meet people's knowledge needs in various ways.

However, if we delve into these efforts in the library industry, we can find that the efforts of the library are a continuation of the information resource provision service of traditional libraries. That means the library strives to provide readers with knowledge existing in their ancestral form in different ways that the readers select, use and accept as much as possible, rather than processing, organizing, and reorganizing the knowledge content. While the information resource-provision service can certainly meet the traditional needs of some readers, it has a large gap with the requirements of the majority of readers in the real network environment for the actual demand and utilization of knowledge and information. The difference lies in the fact that for a long time, the knowledge products that the library people are pursuing and exploring, which aim at the knowledge contents needed by readers and are produced through knowledge organization and processing or knowledge mining, have not appeared in large numbers. The main work done by the library on knowledge information is to classify the knowledge and information according to their external characteristics and content characteristics, to facilitate the user's acquisition, with the provision of the carrier of the knowledge required by the user. The organization and processing tasks of the users' required knowledge content are still done by the users 
themselves. With the rapid development of digitalization of library resources, the information resources available for full-text search are already very rich, and the basic conditions for the production through knowledge mining of the knowledge products that people need are already available.

Looking through the status quo of the development of the library industry, in general, the library industry faces the following situations: First, the public's dependence on the library is not high, and both the number of readers and their frequency of use of library resources are growing very slowly. Second, compared with the utilization rate of network search engines, the utilization rate of information resources of online libraries is slowly increasing.

An important reason for the condition mentioned above is that the mobile Internet is becoming an essential lifestyle for modern people. However, there is still a big gap between the network utilization methods of library information resources and the ways and habits of modern users to utilize knowledge. Through an analysis of the backgrounds of modern people's growth, we can find that modern people were born in the rise of computers and networks, they have become attached to the Internet since childhood. As the "indigenous population" of the Internet age, the network is indispensable for their life, entertainment, learning, and work. After a century of development, modern libraries have always been intertwined and entangled in the inertia of traditional services and the impact of modern methods. With the rapid growth of modern technology, the information resources environment is changing with each passing day, which is constantly impacting and squeezing the service space of library's information resource, threatening the library's living space. If the library only relies on beautifying the humanistic space environment and expanding massive information resources and lacks free, convenient and fast network utilization, it is difficult for modern people to use the library as a way of life and learning. Especially in the face of mobile social networking media that can be used anywhere, pleasing to the eye, convenient and fast, the high-end atmosphere of the library and the scattered knowledge contents can only gradually drift away from modern people.

Through an analysis of the current behavior of users using mobile network information, we can find that the frequency of users searching through Google, Baidu and other search engines to acquire knowledge is increasing year by year. A cruel fact is that few users start information retrieval through the library portal. The author also surveyed the starting point of information retrieval in the Literature Retrieval course, in which $90 \%$ of the students answered that they started information retrieval at search engines and they have the experience of "search on Baidu for domestic affairs, and on Google for foreign affairs". No one had used the library as a starting point for information retrieval. This situation had no significant change even after the end of the Literature Retrieval course. According to a report released by China Internet Network Information Center in July 2013, as of the end of June 2013, the number of search engine netizens in China has reached 470 million, an increase of 19.28 million compared with the end of 2012, and the usage rate of search engine of netizens is $79.6 \%$. The online "PX" entry incident that attracted everyone's attention in April this year fully confirmed this fact. As is well known, the openness, interactivity, uncertainty, and erroneousness of online entries are objective facts. But people are accustomed to searching through the Internet at the first time when they need to acquire an aspect of knowledge, even though the information and knowledge they obtained are bad or good, people would not use the knowledge of the library to distinguish and replace them. What is the reason? It lies in the fact that the network utilization of library knowledge lacks convenient and fast channels, thus cannot become a habit of readers. Let's analyze the process of using library knowledge through the network: to use the resources of the library (or the current digital library, mobile library) through the network, people must first log in to the library portal, register information, or enter Reader ID numbers, barcodes, etc. The most important thing is that the research results obtained by the user are only books, journals, articles, reports, etc. that contain the information contents of the user's desired topics, etc. The users also have to read, find and identify these books, journals, articles and reports to get the desired knowledge. The process requires the user to overcome difficulties and spend a lot of time and effort. It conflicts with the real-time, convenient and fast information requirements of modern users.

As a result, as you can imagine, on the one hand, a significant amount of inaccurate and unreliable knowledge information is flooding the network. In the era of increasing popularization and the younger tendency of mobile network users, [4] the possibility of inaccurate and unreliable knowledge information misleading network users is rising. Some users know perfectly well that networked knowledge is sometimes unreliable and non-authoritative, but for the sake of convenience, they still use the network as the primary channel for obtaining information. On the other hand, as library resource data cannot be quickly and conveniently used by network users, the authoritative knowledge information of library cannot become the primary channel for obtaining information on the network. As a result, the knowledge which is easily accessible is often not authoritative and credible; authoritative and credible library knowledge is not easily accessible. In the long run, how can the library's knowledge guarantee function be realized? At present, search engines are also taking various improvement measures against the weakness of non-authority of their knowledge information. For example, since 2009, Baidu Encyclopedia has launched an "authority co-construction plan" to certify and co-edit the relevant entries through cooperation with third-party authorities, higher educational institutions, government institutions and well-known enterprises. The authoritative construction of the encyclopedia entries "editable by everyone" aims to improve the quality of professional entries further and create a scientific, authoritative and trustworthy online Chinese encyclopedia of knowledge. There is no doubt that 
this is further penetration of the library's information resource guarantee function.

In this circumstance, should the library industry think carefully: Can the library combine the technology and audience advantages of social media with the strength of library knowledge content to realize the perfect combination of information service contents and channels, to expand the new space for the development of libraries?

\subsection{The Application Status of Social Media in the Library Industry}

Recently, Chinese libraries have gradually begun to use applications such as WeChat, microblog to carry out library services. The author investigated the basic situation of the application of WeChat and microblog in some libraries in China:

\subsubsection{The Status of the Utilization of WeChat and Microblog by Libraries}

Table 1. The status of the utilization of WeChat and microblog by libraries.

\begin{tabular}{|c|c|c|}
\hline Library & Application of WeChat & Application of Sina microblog \\
\hline $\begin{array}{l}\text { Tsinghua University } \\
\text { Library Thu-lib }\end{array}$ & $\begin{array}{l}\text { Regularly publish news and library resources, and fully } \\
\text { communicate and interact with users through text, pictures and } \\
\text { voice. Publish hot news about school or library affairs, select } \\
\text { new books for the library collection, add the introduction of } \\
\text { new electronic resources and new technology and new services, } \\
\text { as well as an introduction of a group of treasures and special } \\
\text { collections. Query the common information of the library; learn } \\
\text { how to interact with the Tsinghua Library WeChat online. }\end{array}$ & $\begin{array}{l}\text { In December 2010, the microblog account named "Tsinghua } \\
\text { University Library" was opened on Sina microblog to release } \\
\text { the latest announcements and resource information of the } \\
\text { library to answer readers' queries and respond to readers' } \\
\text { opinions. On September } 22,2012 \text {, "Microblog Consulting" } \\
\text { was officially added to the library virtual reference service } \\
\text { platform, which officially became the fifth consulting method } \\
\text { provided by the library for readers with } 45,099 \text { fans, } 6,232 \\
\text { blog posts and } 374 \text { followers. }\end{array}$ \\
\hline $\begin{array}{l}\text { Peking University } \\
\text { Library pkulib_1902 }\end{array}$ & Online interaction with readers & $\begin{array}{l}\text { As a channel for interacting with readers. It has } 6335 \text { fans, } \\
\text { released } 1012 \text { blog posts, and } 30 \text { followers. }\end{array}$ \\
\hline $\begin{array}{l}\text { Shenzhen Library } \\
\text { szlibrary }\end{array}$ & $\begin{array}{l}\text { (1) Automatic intelligent query answering. (2) Artificial } \\
\text { real-time interactive question answering. (3) Message push, } \\
\text { achieve accurate message push through user grouping and } \\
\text { geographical control. (4) Application functions, including: } \\
\text { Shenzhen Library service: binding and reporting the loss of } \\
\text { reader's card, querying books, borrowing information, } \\
\text { extending the book borrowing period, renewal of reader's card, } \\
\text { self-service deduction from prepayment, etc. }\end{array}$ & $\begin{array}{l}\text { As a channel for information release and interaction with } \\
\text { readers. It has } 62,308 \text { fans, released 2,569 blog posts, and } 365 \\
\text { followers. }\end{array}$ \\
\hline University Town Library & $\begin{array}{l}\text { Lecture pre-announcement, training and reader activity } \\
\text { information release and library service consultation. }\end{array}$ & $\begin{array}{l}\text { Open Tencent microblog as a channel of information } \\
\text { interaction. }\end{array}$ \\
\hline $\begin{array}{l}\text { Guangdong University of } \\
\text { Foreign Studies Library } \\
\text { gdufslib }\end{array}$ & $\begin{array}{l}\text { Book retrieval function, personal information function, access } \\
\text { to user's personal information, borrowing records, appointment } \\
\text { records, historical borrowing records, and visitors to the library } \\
\text { on the same day }\end{array}$ & $\begin{array}{l}\text { As a channel for information release and interaction with } \\
\text { readers. It has } 16393 \text { fans, released } 1211 \text { blog posts, and } 966 \\
\text { followers. }\end{array}$ \\
\hline $\begin{array}{l}\text { National Library of } \\
\text { China }\end{array}$ & $\begin{array}{l}\text { Introduce the collection of featured resources and push cultural } \\
\text { information. }\end{array}$ & $\begin{array}{l}\text { It was opened on May } 6,2013 \text {, used for pre-announcement } \\
\text { setting, classic daily reading, weekly library (recommending } \\
\text { related collection database of National Library of China), } \\
\text { book recommendation, quality books, library news, industry } \\
\text { news, etc. It has } 170,459 \text { fans, released } 2756 \text { blog posts, and } \\
59 \text { followers. }\end{array}$ \\
\hline
\end{tabular}

Deadline: June 02, 2014.

Upon analysis of the contents of the above table, we can find that at present, the library's use of WeChat and microblog is mainly: First, the use of information dissemination. WeChat and microblog as information dissemination channels realize the rapid dissemination of library information by utilizing their audience advantages. Second, instant consultation. Utilize the instant interaction function of WeChat and Weibo to realize full communication and interaction with users through text, pictures and voice to enhance the instant service function of the library. Third, through the linkage to the library portal through WeChat and microblog. Through the link with the library's gateway of automation management system, the library resource retrieval and reader-related information retrieval are realized.

Through the analysis of the application status of the library on social media, it can be found that the library only uses the social media platform as a kind of information channel, or as a new way to carry out library-related services. The purpose is solely for publishing information and Interaction with readers, etc. Therefore, the use of social media features is far from ideal.

\subsubsection{Existing Problems and Analysis of Causes}

Social media wins people's favor by satisfying the practical needs of modern people for acquiring and sharing knowledge information using fragmented time in the high-tempo life and work environment. Through an analysis of the motivations of modern people to use the fragmented time to acquire knowledge, it can be roughly divided into two situations: first, the needs for quick knowledge answering. That is, the reader is unclear about a particular problem, hoping to get accurate 
and authoritative answers quickly; second, the need for rapid knowledge navigation. That is, the reader needs to have a deeper understanding or research on a particular topic, hoping to obtain a wealth of relevant information and to quickly find out the path and method of obtaining materials using fragmented time, or hoping to first use fragmented time to learn some simple material information and then judge whether it needs to obtain further detailed materials. Based on this, in order to meet the needs of modern users to utilize network knowledge, social media library with social media as the platform and library knowledge as the content must be established.

Seeing from the current development situation of the library industry around the world, the library's existing service platforms, including library joint consulting platform, library automation management platform, digital library, etc. Those platforms are incomparable with current mainstream social media platforms such as WeChat and microblog at the technical level and functional applications, especially in the degree of adaptation to and satisfaction of users' behaviors and methods for the use of information.

If social media connects to the library, it will give users quick access to the library's information resources. If the knowledge content of the library can, through reorganization and discovery of library knowledge, become the knowledge content that users can quickly search and obtain through social media, then the search of social media library which is more reliable and credible will replace the online search tools to become a true social knowledge guarantee. At the same time, the user experience provided by social media will greatly reduce the widening distance between users and libraries. Upon the network experience analysis of people's use of knowledge, it is found that the difficulty in knowledge search and the lack of active services are important reasons for the widening distance between libraries and users. The current provision and directional push of library knowledge to users according to their needs is the goal that the library has been pursuing for a long time. The traditional knowledge service of the library is based on the needs of the readers. But in reality, the library usually provides passive information services based on the reader's needs, rather than active services. [5] An important feature of social media is that it can record and track the user's search habits, speculate the preferences of the user's search, and automatically submit or recommend the information and knowledge that the user may need, and the user can actively accept it selectively. [6] The social media platform can also automatically adjust or correct the submitted or recommended information according to the information accepted by the user, in order to provide more accurate and more satisfying information to the user. The social media can also perform data analysis on the subject content, usage habit, frequency and objects of interest that the user pays attention to base on the behaviors of the user when utilizing the information resources. And thereby actively pushes relevant topics, contents and exchange objects to users for their selection; these service methods the libraries have been studying for a long time and seldom use are now widely used in social media, significantly improving the users' utilization efficiency of knowledge while giving them a surprising use experience, so that users can't do without them.

If the social media and the library are integrated with each other, the reorganized and processed knowledge content provided by the library to readers will be actively provided by the social media in a way satisfying the user's needs. Social media will become a reliable and credible knowledge provider in the network environment due to the introduction of library search. And it will enhance the utilization function and utilization value of social media, creating better social value and image; due to the introduction of social media, the user experience of the library will be fundamentally improved, and a large number of social media users will be brought to the library. Complementarity and promotion are the natural advantages of cooperation between social media and libraries. The win-win cooperation between the two is expectable.

\section{The Path of and Challenges Faced by the Cooperative Development Between Social Media and Library}

The cooperation between libraries and social media meets the development needs of their respective industries. To realize the cooperation between libraries and social media, the technical realization method, the cooperation model and related copyright issues must be solved.

\subsection{Technical Realization Method}

Direct access to the required knowledge and information content is a realistic requirement for the knowledge audience in the fast-paced life, which is also the main reason why the audience is willing to use the network. The audience requires the presentation of knowledge content; the library only presents the carrier containing the knowledge content; the user requires quick and accurate access to the knowledge answer, and the library only provides the carrier that may contain the answer. This is an important reason for the low utilization rate of the library network. To fundamentally solve this problem, the provision of fragmented library knowledge content will become a necessary condition.

To solve the problem of technical realization method, two problems must be solved. First, the interface between social media and library knowledge resources. Second, organize the library knowledge content into fragmented knowledge units and present them intelligently.

The service platform construction of social media and library knowledge resources all have their technological realization methods, but the open interface has become a trend Recently, WeChat has taken the lead in announcing the open interface, so that there is no obstacle existing with the interface technology. [7]

The organization of the knowledge content in the library into fragmented knowledge units involves the knowledge discovery and knowledge reorganization of the library. After years of digital library construction, a large number of library 
resources have been digitized, providing a basis for targeted knowledge discovery and knowledge reorganization. The establishment of a scientific presentation sequence for knowledge units formed through knowledge discovery and knowledge reorganization is a vital link to ensure search results and user experience, and is a guarantee of user experience, therefore relevant rules must be scientifically developed. At present, the knowledge integration and discovery based on multi-type resources being carried out or proposed by library consortia at multiple places will provide more precise and more realistic conditions for the construction of social media libraries.

\subsection{The Business Model of Cooperation Between Social Media and Library}

In the era of market economy, the business model is the fundamental element supporting the sustainable development of a cooperative union. As a business enterprise, social media is aimed at satisfying market needs and maximizing business value. Its growth and application of the most advanced technologies and innovation motivation to continuously tap the needs of users are aimed at maximizing corporate development and corporate profits. Its development must be combined with business models. The library provides the broadest social knowledge guarantee, which is the professional responsibility and mission given by the society. Its nature of public welfare determines its characteristic of free service. It just happens to provide a sound business development model for the cooperation between social media and libraries, becoming the basis for achieving a win-win situation.

The number of users and utilization rate are essential factors in the Internet business model. [8] Social media and library have strong functional complementarities. The development of social media cannot do without libraries. In the fierce market competition, social media must continuously optimize its functions and contents. The diversity of people's social contact forms means that unchanged social contact forms are difficult to meet individual needs. How to maintain user stickiness in the process of change is an important issue that social media has to face for a long time. According to the Research Report on Chinese Social Application User Behavior 2013 released by CNNIC, when some users thought that these applications are not necessities, they would reduce usage of them which led to decreased activity. "Social networking websites waste time" was the primary reason for the decline in the degree of Internet users' activity. Among the people with declining degree of activity, $43.1 \%$ thought it wasted too much time, and $40.1 \%$ thought microblog spent too much time. According to statistics, as of December 2013, the number of microblog users in China was 281 million, a decrease of 27.83 million from the end of 2012 , down by $9.0 \%$. The usage rate of microblog among netizens was $45.5 \%$, which was 9.2 percentage points lower than the end of the previous year. In the cooperative construction of social media libraries, social media can take advantage of the intervention of libraries to develop into a content providing platform from an information exchange platform, becoming the provider of authoritative knowledge in the network environment. Thereby, the use value and user viscosity of the platform will be further expanded, and the comprehensive service capability of the platform will be improved. It solves the problem of the lack of reliable, knowledgeable and censored knowledge sources in an open and interactive network environment. At the same time, some readers of libraries can also be converted into social media users. It will further increase the number of users and utilization rate of social media, further increasing the commercial value.

As a knowledge guarantee institution of public welfare nature, the library has no utilitarianism or benefits in the cooperation with social media. [9] The library only hopes that the substantial user groups of social media can become the reader group of the library, and that through the cooperation with social media users can gain extensive access to and quick and convenient use of library knowledge. It makes it unnecessary for social media to increase any financial burden and revenue pressure when accepting the integration of library knowledge services. Therefore, just like the commercial applications available for selection by users in the integration process of social media, such as mobile payment, application software, games, tools, etc., the free integration of library knowledge resources will undoubtedly increase the comprehensive service capabilities of social media, increase the user's dependence, and further enhance the utilization value of social media. However, both parties shall agree that social media must not obtain any economic benefits in any way through the use of library knowledge resources by users. At the same time, libraries must assume responsibility for the authority and reliability of the knowledge provided. As a comprehensive service platform for library resources, social media does not assume any responsibility arising from library knowledge and services.

Therefore, the cooperation between the library and social media meets the requirements of the development goals of both the library and the social media. The "social media library" transforms social media into a knowledge resource center. At the same time, the library has also changed from a single resource center to an interactive platform for communication and exchange function. [10] Although the social media library itself cannot obtain benefits through the provision of knowledge, its enormous commercial added value enables the cooperation between the two parties to promote mutual development in a higher degree of interdependency.

\subsection{Copyright Protection Model}

The cooperation between libraries and social media brings greater copyright risks while making the dissemination and sharing of library knowledge resources more convenient and casual. Therefore, solving the relevant copyright issues properly is the key to the success of the cooperation.

Different with Google Books' model of self-construction of digital libraries through purchase of copyright and Wikipedia and Baidu Knows' model of construction of a knowledge base 
through network interaction, [11] except for works expiring the term of copyright protection, the knowledge disseminated by the library generally has the problem of copyright protection, libraries must follow the relevant requirements of copyright and the provisions on reasonable use of copyright. Limit the ways by which users use knowledge resources. For example, the basic principles of copyright protection must be observed. The control knowledge is restricted for the use of personal study and scientific research. The knowledge disseminated is small and indicated the source, and may not be used to obtain benefits, and may not be copied and disseminated in large quantities and may not affect the sales of works. The fundamental principle to be followed by libraries is that due to their nature of public welfare, libraries cannot obtain any economic benefits through knowledge services. Libraries must comply with the relevant provisions of the Copyright Law. If the library wants to carry out the widest possible knowledge dissemination, it must strive for the widest possible copyright license. [12] to obtain the right of wider and free distribution.

In the era of big data and cloud computing, library knowledge resources have a wide range of sources, complex structures and different situations of copyright. In an open and free Internet environment, people with different cultural backgrounds and different value orientations have different needs when using knowledge resources, and have different usage behaviors and habits; therefore, it is difficult to control copyright risks through users' self-discipline or improvement of copyright protection related awareness. Scientifically designing the technical measures of copyright protection and regulating the behavior of users in using knowledge resources, will be the most important task for social media libraries to reasonably avoid copyright risks. [13] For example, through the technical limitations of the platform, the user search results are limited by the number of words, and the linkage to the source of information and author information are enforced; mandatory reminder to use resources regularly, fulfill the obligation of reminder; limit the provision of full text, limit the mode and scope of dissemination of the full text; [14] through technical restrictions to minimize the uncontrollability of copyright protection. At the same time, ensure not to get any benefit through the social media library. [15] In this way, when in the face of possible copyright action, social media libraries can maintain an advantageous position to avoid copyright risks effectively.

In fact, copyright has undergone some new changes in aspects of information dissemination based on personal use. Recently, the Google \& Authors Guild book-scanning copyright case has fully confirmed this point [16]: Chen Zhuoguang, a Chinese judge in the Manhattan Federal District, ruled that Google just presented part of the books scanned by it rather than selling them, which would help readers find new books that will bring "new income" to authors, and Google "does not engage in direct commercialization of copyrighted works." Thus, "Google Books has provided significant public interest" and called it "an essential research tool". Therefore, we can compare the social media library with it: not directly engaged in commercial activities, not obtain benefits by presenting knowledge information, but only presenting very few contents to the netizens, helping readers to find complete knowledge resources. Obviously, the existence and development of social media libraries are full of imagination.

\section{Conclusion}

Mobile network of social media users has quickly become the main communication tool of network users, and, due to large amounts of network knowledge using the tool, the utilization of the library knowledge resources fell sharply. The library makes full use of social media technology advantage with users, combined with the advantages of library knowledge content, the content and the perfect combination of channels, information service become the inevitable choice of library industry development. Library to achieve full cooperation with social media, promote collaboration both sides win, must solve proper technical implementation methods, common cooperation business model and the related copyright problem.

\section{Funding}

This paper is one of the achievements of the China's national social science fund project, "in the mobile Internet environment, the library and social media cooperative innovation development research"; Item number: 15 BTQ008.

\section{References}

[1] In Q1, 2014, Facebook had more than 1 billion monthly active users at the mobile side.199IT Internet TMT data: Chinese Internet Data Research Information Center-199IT. [EB/OL] [2014-5-3] http://www.199it.com/archives/213087.html.

[2] Twitter's average daily active users exceed 200 million, a total of 400 million tweets was posted each day.199IT Internet TMT data, Chinese Internet Data Research Information Center -199IT.[EB/OL][2014-5-3] http://www.199it.com/archives/101807.html.

[3] The 42nd China Internet Network Development Statistics Report. China Internet Network Information Center. [EB/OL] [2018-8-29] http://www.199it.com/archives/762889.html.

[4] Wang Yingqi. Reading Demands of Rural Dyslexia Groups and Research on Library Reading Care Strategies [J]. National Library of China Journal. 2013 (6): 80-86.

[5] Chen Wei and Wang Qiong. About the mobile Internet environment and social media library cooperative innovation thinking [J]. Intelligence Theory and Practice, 2017, 40 (03):20-23.

[6] Zhang ningning. The four characteristics of social media [J]. News study Tribune, 2016, 7 (15):212.

[7] Wang zhi jin, Wang Xuan、Ma Jing. The ten principles of the theory of knowledge organization [J]. Journal of the national library, 2012, 21 (4):3-11. 
[8] Xiao-bo wu etc. Based on the value network business model classification research perspective: in modern service industry, for example [J]. Journal of zhejiang university (humanities and social science edition), 2014, 44 (02):64-77.

[9] Cheng huan-wen. Definition of library rights [J]. Journal of Chinese library, 2010, 4 (02): 38-45,

[10] Fan binshi. Library Bill of Rights:Rights and User Rights [J]. Journal of the library, 2013 (02): 1-4,

[11] An Xiaolan. An Analysis on Google's Open E-Book Business Model and Its Innovativeness [J]. Journal of shandong normal university (humanities and social science edition), 2012, 57 (02): 141-145.

[12] Chen Wei and Wang Qiong. Research on Copyright Licensing Mode in Library Perspective [J]. Intelligence Theory and Practice, 2011 (4): 54-57,

[13] Cao Shujin etc. An Analysis on Google's Open E-Book Business Model and Its Innovativeness [J]. Journal of university library, 2017, 35 (3): 69-78,

[14] Zeng Yongmei, Zhang Wende. A Probe into Network Information Resources Copyright Risk Evolution and Simulation Dynamics [J]. Information and Documentation ervices, 2017 (02):36-42.

[15] Huan guobin. Suggestions On Avoiding Copyright Infringement:Based on Copyright Exceptions Applicable to Library World [J]. Library Journal, 2012, 31 (10):12-17.
[16] Google wins book-scanning copyright case against Authors Guide: ruling the scanning as fair use -TOM IT channel. [EB/OL]

[2013-11-18].http://it.tom.com/721464/845686457227b.shtml

\section{Biography}

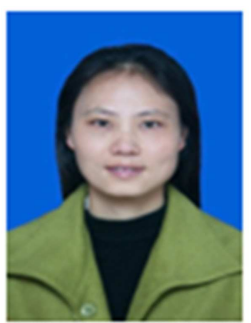

Wang Qiong, born in 1966, Deputy Director, Research Librarian of the Library of Dongguan University of Technology, Dongguan ,China; Research direction: Library Management and Services

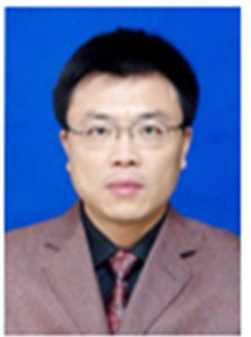

Chen Wei, born in 1966, Research Librarian of the Library of Dongguan University of Technology, Dongguan ,China; Research direction: Library Management Library Intellectual Property 